\title{
DIVORCED WOMEN: Individual Differences in Stressors, Mediating Factors, and Adjustment Outcome
}

\author{
Vicki Garvin, Ph.D., Neil Kalter, Ph.D., James Hansell, Ph.D.
}

Individual differences in exposure and response to stress in a sample of 56 divorced mothers were examined. Compared with normative data, the sample reported significantly more negative life events, more psychiatric symptoms, and poorer social adjustment. Social support and income emerged as the mediating factors most strongly associated with adjustment outcome.

$\mathrm{W}$ Then marriages end in divorce, the former partners typically experience acute emotional distress. Intense anger, depression, diminished self-esteem, heightened anxiety, and feelings of betrayal and abandonment are common (Kelly, 1982; Wallerstein \& Blakeslee, 1990). Although this acute upset often subsides with time, giving way to feelings of renewed competence, relief, and increased self-esteem (Hetherington, Cox, \& Cox, 1982), many divorced people continue to struggle with the disruptions of postdivorce living. Even years after the marital separation, a significant minority continue to report high rates of depression, unhappiness, loss, anger, and sexual dissatisfaction (Bloom, Hodges, Kern, \& McFaddin, 1985; Wallerstein \& Blakeslee, 1990).

Although researchers have made significant progress in understanding the emotional turmoil of the initial separation period, relatively little is known about longterm divorce-related stressors. Due to the longstanding bias toward locating the causes and consequences of divorce in the individual, even less is known about external mediating factors, such as social support, that might buffer or potentiate the harmful effects of stress. Because earlier research efforts typically compared the well-being of divorced persons with the well-being of persons in intact first marriages, not much is known about individual differences in coping and adjustment within the group of divorced persons. Studies of relative adjustment outcome have rarely employed multiple measures and, if outcomes were measured at all, have generally underrepresented positive ones.

To address these concerns the present study examined individual differences in stressors, mediators, and adjustment outcomes within a sample of divorced women, comparing the relative well-being of divorced single women with that of divorced remarried women and focusing on those mediating factors that are potentially modifi-

Based on a paper presented to the 1989 annual meeting of the American Orthopsychiatric Association in New York. Authors are at: Glastonbury Psychological Associates, P.C., Glastonbury, Conn. (Garvin); Center for the Child and Family, University of Michigan (Kalter), and Psychological Services Clinic (Hansell), Ann Arbor, Mich. 
able, i.e., accessible to intervention. In response to the methodological issues reviewed above, this study included 1 ) both aggregated and disaggregated measures of stress, 2) a range of situational and personal mediating factors, and 3) multiple measures of negative as well as positive outcome.

\section{METHOD}

\section{Subjects}

The study explored the relationships among stressors, mediators, and adjustment outcome for a sample of divorced mothers with at least one elementary schoolage child. This particular group was selected because women with minor children represent the most common subgroup of divorced women (National Center for Health Statistics, 1985).

Subjects were drawn from mothers of children in four public elementary schools located in southeastern Michigan. Approximately $45 \%$ of the divorced mothers agreed to participate, which compares favorably with participation rates of similar projects (Stolberg \& Garrison, 1985). Our sample includes 56 white women aged 29 to 46 $(M=35.25, S D=3.95)$. Of the 56 women, 37 were divorced and single, and the remaining 19 had remarried. Duration of marriage before divorce ranged from slightly less than two years to $161 / 2$ years $(M=$ 9.04, $S D=3.92$ ), with the time since divorce ranging from seven months to $11^{1 / 2}$ years $(M=5.19$ years, $S D=2.93)$. Families had from one to five children currently living in the household $(M=2.23, S D=$ $1.01)$. Socioeconomic status ranged from Hollingshead Class I to Hollingshead Class IV (Hollingshead, 1972), with the majority of subjects in Class II. Family income ranged from a low of $\$ 4,000$ to a high of over $\$ 75,000$, with average household income approximately $\$ 20,000$.

\section{Procedure}

Through a 20-minute telephone interview, a week-long diary, and a $2 \frac{1}{2}$-hour home visit, information was collected on various kinds of stressors (major life events, daily hassles, and divorce-specific stressors), potential mediators (at the individual, familial, and extrafamilial level), and adjustment outcomes (psychiatric symptoms, social adjustment, and daily health and mood).

\section{Instruments}

Life Experiences Survey (LES). This is a 47-item self-report measure that asks respondents to indicate which life events they have experienced during the past year ( $\mathrm{Sa}$ rason, Johnson, \& Siegel, 1978). The LES yields three scores: positive change, negative change, and total change. Test-retest reliability results in correlations of .53 (positive change), .88 (negative change), and .64 (total change). The negative lifechange score is significantly related to several stress-related dependent measures, providing support for convergent validity (Sarason, Johnson, \& Siegel, 1978).

Hassles Scale (HS). This is a revised version of the Hassles and Uplifts Scale originally developed by Kanner, Coyne, Schaefer, and Lazarus (1981). The present instrument, which was redesigned by DeLongis, Folkman, and Lazarus (1988), assesses minor difficulties and irritants in the following eight areas: household, finances, work, home maintenance, health, personal life, family and friends, and environmental and social issues. Of the 53 revised items, 17 that loaded at less than .32 on their respective factors were eliminated. Alphas for the revised factors range from .51 to .90 .

Self-Esteem Inventory (SEI). This is a tenitem self-report measure that assesses feelings of self-worth and personal adequacy (Rosenberg, 1965). Internal consistency, as measured by coefficient alpha, yields a correlation of .76 . Test-retest reliability results in a correlation of .85 . Comparisons with four other measures of self-esteem result in correlations ranging from .56 to .83 , providing support for convergent validity (Weiss \& Knight, 1980). 
FACES III. This is the third and most recent version of a 20 -item self-report inventory designed to assess family cohesion and adaptability (Olson et al., 1985). Internal consistency, as measured by Cronbach's alpha, results in correlations of .77 (cohesion), .62 (adaptability), and .68 (total). FACES III discriminates extremely well between problem families and nonsymptomatic families (Olson et al., 1985).

Social Support (SS) questionnaire. Our version is a 63-item self-report inventory adapted from the social-support questionnaire developed by Bloom, Hodges, and Caldwell (1983). Divorced mothers are asked to rate how much support is needed, how much support is available, and how satisfied they are with support received in nine need areas. These nine domains, previously identified as areas of concern for divorced parents (Bloom, Hodges, \& Caldwell, 1983; Hetherington, Cox, \& Cox, 1978), include child care, finances, discussing feelings, recreational and social activities, physical intimacy and sexual needs, discussing divorce-related concerns, career and employment, housework and homemaking, and legal matters.

Brief Symptom Inventory (BSI). This is a 53-item self-report symptom checklist that yields nine specific symptom dimensions (somatization, obsessive-compulsive, interpersonal sensitivity, depression, anxiety, hostility, phobic anxiety, paranoid ideation, and psychoticism) and three global indices of functioning (the global severity index, the positive symptom distress index, and the positive symptom total) (Derogatis \& Spencer, 1982). Test-retest reliability results show correlations ranging from .68 to .91 for the symptom dimensions and from .80 to .90 for the three global indices. Evidence for convergent validity with the Minnesota Multiphasic Personality Inventory (MMPI) is impressive (Derogatis \& Spencer, 1982).

Social Adjustment Scale (SAS). This is a 42-item self-report questionnaire that measures instrumental or expressive role- performance in six major areas: work as job-holder, housewife, or student; social and leisure activities; relationships with extended family; marital role as spouse; role as parent; and role as member of the family unit (Weissman \& Bothwell, 1976). Internal consistency, as measured by coefficient alpha, yields a correlation of .74. Testretest reliability results show a correlation of .80 (Weissman, Prusoff, Thompson, Harding, \& Myers, 1978). Higher scores on this measure indicate worse adjustment.

Daily Health (DH) and Daily Mood (DM) ratings. These are designed to assess dayto-day fluctuations in physical and emotional well-being and are adapted from Verbrugge (1980). Verbrugge's review provides extensive justification for the superiority of the health-diary format.

\section{RESULTS}

\section{Descriptive Analysis}

First, the sample was characterized descriptively using the demographic data obtained from the telephone interview.

Using survey data reported by the $\mathrm{Na}$ tional Center for Health Statistics (1985), the sample was compared to the national group of divorced women and was determined to be typical of divorced women nationwide in terms of duration of marriage before divorce and of number of children. The sample was, however, significantly younger at age of marriage $(t=8.27$, $p<.001)$ and at time of divorce $(t=5.82$, $p<.001$ ).

To determine if higher stress was significantly related to poorer outcome, and to justify the application of multiple tests for separate outcome measures, both the macro measure of stress, the Life LES, and the micro measure of stress, the HS, were dichotomized using a median split. Subjects scoring above the median were identified as belonging to the high-stress group. A multivariate ANOVA, with major life events as the independent variable and psychiatric symptomatology and social adjustment as the dependent variables, showed macro 
stress to be significantly related to macro adjustment outcomes $(F=4.29, d f=2,50$, $p=.02$ ). With daily hassles as the independent variable and daily health and daily mood as the dependent variables, micro stress was found to be significantly related to micro adjustment outcomes $(F=6.96$, $d f=2,45, p=.002$ ).

The sample was next examined in terms of the three factors of interest: stressors, mediators, and outcomes. TABLE 1 com- pares means and standard deviations for the sample with available normative data. In most cases, the available comparison groups include a mix of single, married, divorced, and remarried persons. These comparisons are, therefore, more likely to underestimate differences between the study's divorced sample and never-divorced women.

In this conservative context, the sample of divorced women was found to experience significantly more negative life events

Table 1

STUDY SAMPLE COMPARED WITH NORM GROUPS

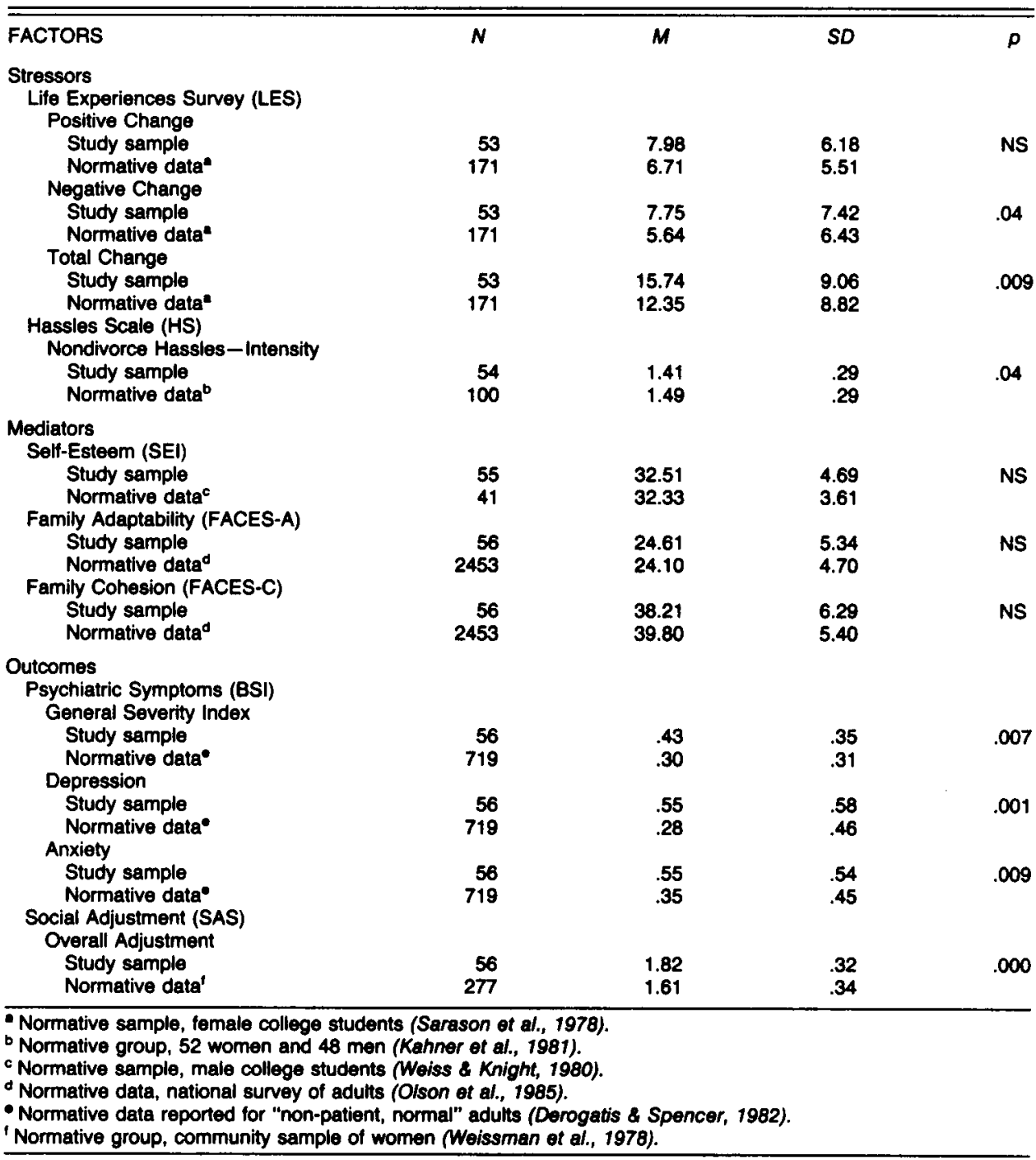


as well as significantly more total life change. With respect to day-to-day upset, the divorced women reported significantly less intense nondivorce hassles. For the mediating factors, no significant differences were found between our group of divorced women and national normative data in terms of self-esteem, family adaptability, and family cohesion. In terms of adjustment outcome, the sample reported significantly more depression and anxiety and poorer social adjustment. There are no relevant norms for daily health and daily mood.

\section{Divorced Single and Remarried Women}

Since these descriptive statistics provide a profile of the research sample in the aggregate, they can obscure subgroup differences in exposure and responsiveness to stress. This aggregated data, therefore, was reanalyzed, this time treating the divorced single women $(N=37)$ and the divorced remarried women $(N=19)$ as distinct subgroups. On the descriptive demographic variables, it was found that the two groups did not differ in terms of age, number of children, custody arrangement, socioeconomic status, work status, duration of marriage, or time since divorce. There was, however, a marked difference in income categories. For the divorced single women, group average income was approximately $\$ 14,000$; for the remarried women, average income was significantly higher, approximately $\$ 42,000\left(\chi^{2}=36.8, d f=18\right.$, $p=.006$ ). The two groups also differed in number of prior marriages, with $43 \%$ of the divorced single women and $100 \%$ of the remarried women having no marriages previous to the marriage that ended in divorce $\left(\chi^{2}=6.25, d f=3, p=.01\right)$.

Significant differences between the divorced single and the remarried women were also obtained on the measures of stress, mediating factors, and adjustment outcome. Compared to their remarried counterparts, the divorced single women experienced significantly more stress, both in terms of total number of major life events $(t=2.20$, $p<.03)$ and in the severity of divorcespecific $(t=3.16, p<.003)$ and nondivorce $(t=2.95, p<.005)$ hassles. With respect to mediating factors, divorced single women scored significantly lower on self-esteem $(t=2.21, p<.03)$ and satisfaction with social support $(t=2.23, p<.03)$. In terms of adjustment outcome, the findings remain consistent: the divorced single women reported more psychiatric symptomatology $(t=2.05, p<.04)$, less adaptive social adjustment $(t=2.72, p<.009)$, poorer daily health $(t=2.34, p<.02)$, and lower daily $\operatorname{mood}(t=2.13, p<.04)$.

In light of these findings, the results reported in TABLE 1 were reanalyzed, this time treating divorced single and remarried women as distinct subgroups. This new set of results, summarized in TABLE 2, showed that it was the subgroup of divorced single women that accounted for the significant differences previously obtained between this sample and the normative groups. Compared to relevant norm groups, the divorced single women experienced significantly more negative life events, total life events, psychiatric symptoms (especially depression and anxiety), and poorer social adjustment. Their remarried counterparts, in contrast, were not remarkably different from the norm groups. Where the remarried women differed, they differed in a positive direction: they reported significantly less intense nondivorce hassles and significantly higher self-esteem.

Starting with stressors, the day-to-day hassles experienced by each group in terms of specific areas of difficulty were then compared. It was found that the divorced single women report significantly greater (i.e., more severe) hassles with finances ( $t=$ $3.24, p=.002)$, health $(t=2.14, p=.04)$, and household $(t=2.32, p=.02)$, with a trend toward more severe hassles in the areas of home maintenance $(t=1.79, p=.08)$ and personal life $(t=1.94, p=.06)$. There were no significant differences between the divorced single and remarried women in terms 
Table 2

DIVORCED SUBJECTS COMPARED WITH NORM GROUPS

\begin{tabular}{|c|c|c|c|c|}
\hline FACTORS & $N$ & $M$ & SD & $p^{b}$ \\
\hline \multicolumn{5}{|c|}{$\begin{array}{l}\text { Stressors } \\
\text { Life Experiences Survey (LES) } \\
\text { Positive Change }\end{array}$} \\
\hline Single & 35 & 8.91 & 6.74 & .06 \\
\hline Remarried & 18 & 6.17 & 4.57 & NS \\
\hline Normative data & 171 & 6.71 & 5.51 & \\
\hline \multicolumn{5}{|l|}{ Negative Change } \\
\hline Single & 35 & 8.71 & 7.66 & .02 \\
\hline Remarried & 18 & 5.89 & 6.73 & NS \\
\hline Normative data & & & 6.43 & \\
\hline \multicolumn{5}{|l|}{ Total Change } \\
\hline Single & 35 & 17.63 & 9.46 & .002 \\
\hline Remarried & 18 & 12.06 & 7.10 & NS \\
\hline Normative data & 171 & 12.35 & 8.82 & \\
\hline \multirow{2}{*}{\multicolumn{5}{|c|}{$\begin{array}{l}\text { Hassles Scale (HS) } \\
\text { Nondivorce Hassles - Intensity }\end{array}$}} \\
\hline Nondivorce Hassle & & & & \\
\hline Single & 36 & 1.49 & .32 & NS \\
\hline Remarried & 18 & 1.24 & .11 & .000 \\
\hline Normative data & 100 & 1.49 & .29 & \\
\hline \multirow{2}{*}{\multicolumn{5}{|c|}{ Mediators }} \\
\hline \multicolumn{3}{|l|}{ Sell-Esteem (SEI) } & & \\
\hline Single & 36 & 31.53 & 5.02 & NS \\
\hline Remarried & 19 & 34.39 & 3.39 & .02 \\
\hline Normative data & 41 & 32.33 & 3.61 & \\
\hline \multicolumn{5}{|c|}{ Family Adaptability (FACES-A) } \\
\hline Single & 37 & 38.05 & 7.01 & NS \\
\hline Remarried & 19 & 38.53 & 4.73 & NS \\
\hline Normative data & 2453 & 24.10 & 4.70 & \\
\hline \multicolumn{5}{|c|}{ Family Cohesion (FACES-C) } \\
\hline Single & 37 & 24.73 & 5.31 & NS \\
\hline Remarried & 19 & 24.37 & 5.53 & NS \\
\hline Normative data & 2453 & 39.80 & 5.40 & \\
\hline \multirow{3}{*}{\multicolumn{5}{|c|}{$\begin{array}{l}\text { Outcomes } \\
\text { Psychiatric Symptoms (BSI) }\end{array}$}} \\
\hline & & & & \\
\hline & & & & \\
\hline Single & 37 & .50 & .39 & .004 \\
\hline Remarried & 19 & .30 & .21 & NS \\
\hline Normative data & 719 & .30 & .31 & \\
\hline \multicolumn{5}{|l|}{ Depression } \\
\hline Single & 37 & .65 & .67 & .002 \\
\hline Remarried & 19 & .34 & .29 & NS \\
\hline Normative data & 718 & .28 & .46 & \\
\hline \multicolumn{5}{|l|}{ Anxiety } \\
\hline Single & 37 & .59 & .58 & .02 \\
\hline Remarried & 19 & .46 & .47 & NS \\
\hline \multirow{2}{*}{\multicolumn{5}{|c|}{$\begin{array}{l}\text { Normative data } \\
\text { Social Adjustment (SAS) }\end{array}$}} \\
\hline & & & & \\
\hline Single & 37 & 1.90 & .32 & .000 \\
\hline Remarried & 19 & 1.67 & .27 & NS \\
\hline Normative data & 277 & 1.61 & .34 & \\
\hline
\end{tabular}

Note. For normative group data, see TABLE 1.

- Not all subjects completed all measures.

${ }^{b} p=$ results of $t$-tests comparing divorced single women and remarried women (treated as distinct subgroups) with established norms.

of severity of hassles with work, environment, or family life.

With respect to mediating factors, there was particular interest in those factors, such as social support and income, that not only distinguish divorced single and remarried women but are also modifiable. Regarding income, it was previously noted that divorced single women reported significantly lower incomes and significantly poorer adjustment outcomes. It is not clear, however, whether marital status per se or in- 
come, which is highly correlated with marital status $(r=.66, p<.0001)$, accounts for the strong relationship between income and adjustment outcome. To resolve this issue, differences in income within the subgroup of divorced single women were examined. Using a median split, the divorced single women who scored above the median were identified as "high income" and women who scored below the median were designated "low income." Comparing these two groups, it was found that low income was significantly associated with poorer macro adjustment outcomes, i.e., with more psychiatric symptoms $(t=2.31 ; p=.02)$ and poorer social adjustment $(t=2.52, p=.01)$. No relationship between income and the two micro outcomes was found.

Due to small sample size, a similar analysis was not attempted for the remarried subgroup. However, a comparison of adjustment outcomes for the remarried women with adjustment outcomes for the highincome divorced single women was made. With respect to psychiatric symptomatology and social adjustment, no significant differences between the two groups were found. In terms of the micro outcomes, remarried women did report significantly better daily health $(t=2.60, p=.01)$ and daily $\operatorname{mood}(t=2.11, p=.04)$.

With respect to social support, it was found that the divorced single women reported a significantly greater need for support in the areas of child care $(t=2.49$, $p=.02)$ and finances $(t=2.24, p=.03)$, with a trend toward significant differences in the area of career $(t=1.82, p=.07)$. The divorced single women were significantly less satisfied with the support they actually received in the areas of finances $(t=3.86$, $p=.0003)$, social life $(t=2.58, p=.01)$, sexual and physical intimacy $(t=2.15$, $p=.04)$, and household $(t=3.15, p=.003)$, as well as overall $(t=2.23, p=.03)$.

Finally, the divorced single and remarried women were compared in terms of the various component factors that comprise the global indices of adjustment outcome. Di- vorced single women obtained higher (i.e., worse) scores on four of the BSI symptom subscales: obsessive-compulsive $(t=2.03$, $p=.05)$, internalizing $(t=2.06, p=.04)$, depression $(t=1.94, p=.05)$, and paranoid $(t=2.19, p=.03)$. On the SAS, divorced single women reported significantly poorer adjustment with current partner $(t=2.12$, $p=.04)$ and with the family unit $(t=2.74$, $p=.008$ ). Divorced single women also evidenced a trend toward poorer adjustment in the social-leisure $(t=1.92, p=.06)$ and extended-family $(t=1.95, p=.06)$ domains. Differences between the two groups did not attain statistical significance on the remaining five BSI factors or two SAS subscales.

\section{DISCUSSION \\ Descriptive Findings}

The descriptive analyses suggest that this sample of divorced women is in general typical of divorced women nationwide in terms of standard demographic features. With respect to age, however, it is significantly younger. Since women who are younger at the time of divorce have been found to fare significantly better than those who are older (Chiriboga, Roberts, \& Stein, 1978; Pais, 1978), these findings presumably represent conservative estimates of stress and adjustment outcome.

It is, therefore, particularly noteworthy that this sample, in comparison to normative groups, reported significantly more negative life events, more total life events, more psychiatric symptoms, and poorer social adjustment. In fact, given that the comparison groups are generally composed of a mix of single, married, divorced, and remarried persons, these results are likely to underestimate differences between the divorced sample and never-divorced women. (Although stress was measured using subjective, selfreport questionnaires, the stress and coping literature [Sarason, Johnson, \& Siegel, 1978; Thoits, 1983] suggests that it is the perception of stress-and not the objective 
extent of the stress - that is most strongly related to adjustment outcome.)

\section{Divorced Single and Remarried Women}

Inclusion of both divorced single and divorced remarried women in the present sample permitted comparisons showing that divorced single women experienced more stress and poorer adjustment outcomes with fewer mediating resources. Thus, it was the divorced single women-and not the sample as a whole-whose scores departed strongly and in a negative direction from normative values. These results confirm and expand on previous findings reported by Bloom, Asher, and White (1978) and Hetherington (1986).

When the global stress factors were disaggregated, it was found that the divorced single women, when compared with the remarried women, reported significantly greater hassles with finances, household, home life, and personal life. Compared to the remarried women, the divorced single subjects scored significantly lower on selfesteem, satisfaction with social support, and income. There were no areas in which remarried women reported greater daily stress or poorer adjustment outcomes than did their divorced single counterparts. It is possible, however, that this could be an artifact of sampling: troubled remarriages may already have resulted in divorce.

Income and social support were further investigated, not only because these two mediators were consistently and significantly associated with adjustment outcome, but because they are accessible to intervention. In contrast to previous research efforts (Spanier \& Lachman, 1980), the goal here was also to disentangle the effects of income and marital status. By examining differences in income within the group of divorced single women, it was possible to confirm the strong relationship between low income and poor adjustment outcome, while controlling for marital status. Our findings suggest that it is not remarried status per se that contributes to better outcome; level of income, regardless of marital status, is strongly linked with quality of well-being. Divorced single women with high incomes not only reported better adjustment outcomes than did divorced single women with lower incomes, but the high-income single women did not differ from the remarried women with respect to psychiatric symptomatology and social adjustment.

In light of these findings, the oftendocumented relationship between marital status and well-being can be reinterpreted. Researchers have traditionally attributed the poorer physical and mental health of single people to the unmet emotional needs and frustrations presumably inherent in being unmarried. It is equally likely, however, that the higher levels of depression and poorer social adjustment frequently reported by single parents - findings that have just been replicated here-can be attributed to the economic hardship, social isolation, and increased work and parenting responsibilities that single parents are both more exposed to and more vulnerable to (Pearlin \& Johnson, 1977).

These findings also suggest the critical role played by formal and informal social support. It was found that the divorced single women reported a significantly greater need for support in the areas of finances, child care, and career; these women were significantly less satisfied with the support they actually received in the areas of finances, social life, sex and physical intimacy, and household. Given these domains of expressed need, it is not surprising that the divorced single women also reported poorer social adjustment with respect to current partner, family unit, extended family, and social and leisure activities. The correspondence is rather striking: the divorced single women reported poorer adjustment in the same areas in which they requested greater social support. These divorced single women seem remarkably aware of their own distress and their areas of greatest vulnerability and need. 


\section{REFERENCES}

Bloom, B., Asher, S., \& White, S. (1978). Marital disruption as a stressor: A review and analysis. Psychological Bulletin, 85, 867-894.

Bloom, B., Hodges, W., \& Caldwell, R. (1983). Marital separation: The first eight months. In E.J. Callahan \& K. McCloskey (Eds.), Life-span developmental psychology (pp. 217-239). San Diego: Academic Press.

Bloom, B., Hodges, W., Kern, M., \& McFaddin, S. (1985). A preventive intervention program for the newly separated: Final evaluations. American Journal of Orthopsychiatry, 55, 9-26.

Chiriboga, D., Roberts, J., \& Stein, J. (1978). Psychological well-being during marital separation. Journal of Divorce, 2, 21-36.

DeLongis, A., Folkman, S., \& Lazarus, R. (1988). Hassles, health, and mood: A prospective study with repeated daily assessments. Unpublished manuscript.

Derogatis, L., \& Spencer, P. (1982). The Brief Symptom Inventory (BSI). Baltimore, MD: Clinical Psychometric Research.

Hetherington, M. (1986). Family relations six years after divorce. In K. Pasley \& M. Ihinger-Tallman (Eds.), Remarriage and stepparenting today: Research and theory. New York: Guilford Press.

Hetherington, M., Cox, M., \& Cox, R. (1978). The aftermath of divorce. In J. Stevens \& $M$. Mathews (Eds.), Mother/child, father/child relationships (pp. 149-176). Washington, DC: National Association for the Education of Young Children.

Hetherington, M., Cox, M., \& Cox, R. (1982). Effects of divorce on parents and children. In M. Lamb (Ed.), Non-traditional families (pp. 233-288). Hillsdale, NJ: Lawrence Erlbaum.

Hollingshead, A.B. (1972). Four factor index of social status. Department of Sociology, Yale University, New Haven.

Kanner, A., Coyne, J., Schaefer, C., \& Lazarus, R. (1981). Comparison of two modes of stress measurement: Daily hassles and uplifts versus major life events. Journal of Behavioral Medicine, 4, 1-39.

Kelly, J. (1982). Divorce: The adult perspective. In B. Wolman \& G. Stricker (Eds.), Handbook of developmental psychology (pp. 734-750). Englewood Cliffs: Prentice Hall.

National Center for Health Statistics. (1985). Monthly vital statistics report (DHHS Publication 33-11). Washington, DC: US Government Printing Office. Olson, D., McCubbin, H., Barnes, H., Larsen, A., Muxen, M., \& Wilson, M. (1985). Family inventories. Family Social Science, University of Minnesota, Minneapolis.

Pais, J. (1978). Social psychological predictions of adjustment for divorced mothers. Unpublished doctoral dissertation, Department of Psychology, University of Tennessee, Knoxville.

Pearlin, L., \& Johnson, J. (1977). Marital status, lifestrains and depression. American Sociological Review, 42, 704-715.

Rosenberg, M. (1965). Society and the adolescent selfimage. Princeton, NJ: Princeton University Press.

Sarason, I., Johnson, J., \& Siegel, J. (1978). Assessing the impact of life changes: Development of the Life Experiences Survey. Journal of Consulting and Clinical Psychology, 46, 932-946.

Spanier, G., \& Lachman, M. (1980). Factors associated with adjustment to marital separation. Sociological Focus, 13, 369-381.

Stolberg, A., \& Garrison, K. (1985). Evaluating a primary prevention program for children of divorce. American Journal of Community Psychology, 13, 111-124.

Thoits, P. (1983). Dimensions of life events that influence psychological distress: An evaluation and synthesis of the literature. In H. Kaplan (Ed.), Psychosocial stress: Trends in theory and research ( $\mathrm{pp}$. 33-103). San Diego: Academic Press.

Verbrugge, L. (1980). Health diaries. Medical Care, 18, 73-95.

Wallerstein, J., \& Blakeslee, S. (1990). Second chances: Men, women, and children a decade afier divorce. New York: Ticknor and Fields.

Weiss, H. , \& Knight, P. (1980). The utility of humility: Self-esteem, information search, and problemsolving efficiency. Organizational Behavior and $\mathrm{Hu}$ man Performance, 25, 216-223.

Weissman, M., \& Bothwell, S. (1976). Assessment of social adjustment by patient self-report. Archives of General Psychology, 33, 1111-1115.

Weissman, M., Prusoff, B., Thompson, D., Harding, P., \& Myers, J. (1978). Social adjustment by selfreport in a community sample and in psychiatric outpatients. The Journal of Nervous and Mental Disease, 166, 317-326. 